\title{
Therapist Driven Rehabilitation Protocol for Patients with Chronic Heart and Lung Diseases: A Real-Life Study
}

\author{
Carla Simonelli ${ }^{1}$, Michele Vitacca $^{2}$, Nicolino Ambrosino ${ }^{3}{ }^{\circledR}$, Simonetta Scalvini ${ }^{1}$, \\ Francesca Rivadossi ${ }^{1}$, Manuela Saleri ${ }^{2}$, Aubin G Fokom ${ }^{2}$, Ilaria Speltoni ${ }^{1}$, Riccardo Ghirardi ${ }^{2}$ \\ and Mara Paneroni ${ }^{2, *(1)}$ \\ 1 Istituti Clinici Scientifici Maugeri IRCCS, Cardiac Rehabilitation of the Institute of Lumezzane, \\ 25065 Lumezzane (BS), Italy; carla.simonelli@icsmaugeri.it (C.S.); simonetta.scalvini@icsmaugeri.it (S.S.); \\ francesca.rivadossi@icsmaugeri.it (F.R.); ilaria.speltoni@icsmaugeri.it (I.S.) \\ 2 Istituti Clinici Scientifici Maugeri IRCCS, Respiratory Rehabilitation of the Institute of Lumezzane, \\ 25065 Lumezzane (BS), Italy; michele.vitacca@icsmaugeri.it (M.V.); manuela.saleri@icsmaugeri.it (M.S.); \\ georges.fokom@icsmaugeri.it (A.G.F.); riccardo.ghirardi@icsmaugeri.it (R.G.) \\ 3 Istituti Clinici Scientifici Maugeri IRCCS, Respiratory Rehabilitation of the Institute of Montescano, \\ 27040 Montescano (PV), Italy; nico.ambrosino@gmail.com \\ * Correspondence: mara.paneroni@icsmaugeri.it; Tel.: +39-030-8253122
}

Received: 18 December 2019; Accepted: 1 February 2020; Published: 5 February 2020

\begin{abstract}
Therapist driven protocols may help to tailor rehabilitation programs to individual patients. We aimed to test the feasibility, safety, and clinical usefulness of a therapist driven protocol for rehabilitation including exercise training of patients with heart or lung diseases. An internal audit elaborated the Cardio-Respiratory Exercise Maugeri Algorithm (CREMA) based on: (a) standardized baseline assessments, (b) decision-making pathways, and (c) frequency/intensity/time/type (FITT) of prescription for each exercise. Outpatients $(n=620)$ with chronic heart disease (CHD), recent myocardial revascularization (REVASC), chronic airway (Obstructive), and restrictive lung (Restrictive) diseases underwent exercise training according to CREMA during 4 years. Peripheral muscle strengthening was the most prescribed exercise $(83.6 \%)$, while arm endurance training was the least frequently $(0.75 \%)$. Exercise prescription varied widely among the disease groups (interval training $19-47 \%$, balance $35-49 \%$, lower limb muscle training 6-15\%). After training, REVASC patients were the best improvers in the 6 min walking distance $(+48.7(56.1) \mathrm{m})$, maximal inspiratory pressure $\left(+9.6(15.4) \mathrm{cmH}_{2} \mathrm{O}\right)$, and daily steps (+1087.2 (3297.1) n/day). Quadriceps and biceps strength, maximal expiratory pressure, and balance improved in all groups, without significant differences. Minor side effects were observed in $11.2 \%$ of the patients. The CREMA therapist driven protocol was feasible, safe, and useful for prescribing tailored training programs. Exercise prescriptions and training response differed among diseases.
\end{abstract}

Keywords: cardiac rehabilitation; pulmonary rehabilitation; exercise; training; algorithm; physiotherapist protocol; driven protocols

\section{Introduction}

Rehabilitation including exercise training is an essential component of the comprehensive management of patients with lung and/or heart diseases [1-5]. There is a large body of evidence showing the benefits of rehabilitation including exercise training on symptom improvement, exercise tolerance, and health related quality of life $[1,2,6]$. However, due to the high prevalence of these diseases, the majority of potential candidates have no access to supervised programs $[7,8]$. In the 
attempt to save resources, allowing a larger delivery to patients, such programs have been proposed for patients with heart or lung disease, as they share similar symptoms and comorbidities $[9,10]$. A recent position paper stated that common training programs administered to patients with heart or lung disease are feasible, safe, and cost-effective for healthcare commissioners, thus improving the access to rehabilitation [11]. There is a lack of access to supervised programs, and the risk of over-standardization for patients with different diseases in such programs could be a problem. The implementation of a therapist driven protocol could reduce this risk.

A driven protocol is defined as a consensus of medical knowledge and opinions based on an operative flow chart according to objective measurable variables and rigid items to reduce operator anarchy in prescription [12]. Driven protocols may help to tailor these programs to the individual patients.

In cardiac field, therapist driven protocols, including tools to evaluate the main targets of exercise-based cardiac rehabilitation, have recently been proposed and decision support systems assisting healthcare professionals to prescribe training programs has been developed $[13,14]$. In these decision support systems $[13,14]$, the authors have proposed only training as the main outcome measure referring to specific disease. Potential limitations of this approach have generated our hypothesis: to propose a new therapist driven protocol for patients with chronic heart and lung diseases including multiple outcomes.

The aims of the study were: (1) to describe the audit process in order to develop a tailored therapist driven protocol for rehabilitation programs, including exercise training, using a battery of evaluation tools common to patients with heart or lung disease; (2) to test its feasibility and safety; and (3) to evaluate the clinical results.

\section{Materials and Methods}

This was a pragmatic study, conducted in the Cardio-Pulmonary Physiotherapy Service of the Cardiac and Pulmonary Rehabilitation Departments of the Istituti Clinici Scientifici (ICS) Maugeri IRCCS, Lumezzane (Brescia), Italy, between January 2015 and December 2018. The Ethics Committee approved the study (CE 2287,14 May 2019). All patients signed an informed consent to the scientific use of their clinical data.

\subsection{Development of the Protocol}

An audit was created (from September to December 2014) in order to review decision-making pathways for training and rehabilitation programs. The audit was composed by a multidisciplinary expert panel (one senior and three junior physiotherapists, two cardiologists, and one pulmonologist). Experts met twice for an audit and were asked to define: (1) the required baseline assessments; (2) the frequency, intensity, time, and type (FITT) of exercise training to be included in the program; and (3) the decision-making pathways to define how the baseline assessment should influence the FITT prescription of each component of the program [15]. Prior to the meeting, a systematic review of the literature was performed, using the keywords: "pulmonary rehabilitation; cardiac rehabilitation, exercise training, inspiratory muscle training, strength training, balance training, physical activity, COPD, idiopathic pulmonary fibrosis, coronary artery disease, chronic heart failure". Experts discussed their real-life experience. During the audit, a driven protocol and operative flow charts were summarized and proposed as a new operational bundle hypothesis based on the literature and consensus. The protocol was a tool for prescription of tailored rehabilitation programs according to the guidelines.

The experts scored the final protocol and flow charts using a Delphi-like procedure [16]. Each items and pathways were deemed approved if at least $75 \%$ of the group rated the proposal with a rating higher than $7(0=$ totally disagreed; $10=$ totally in agreement). Finally, the audit approved the Cardio-Respiratory Exercise Maugeri Algorithm (CREMA) to be used as a guide for prescription of a therapist driven protocol in patients with heart and lung diseases (Figure 1). 


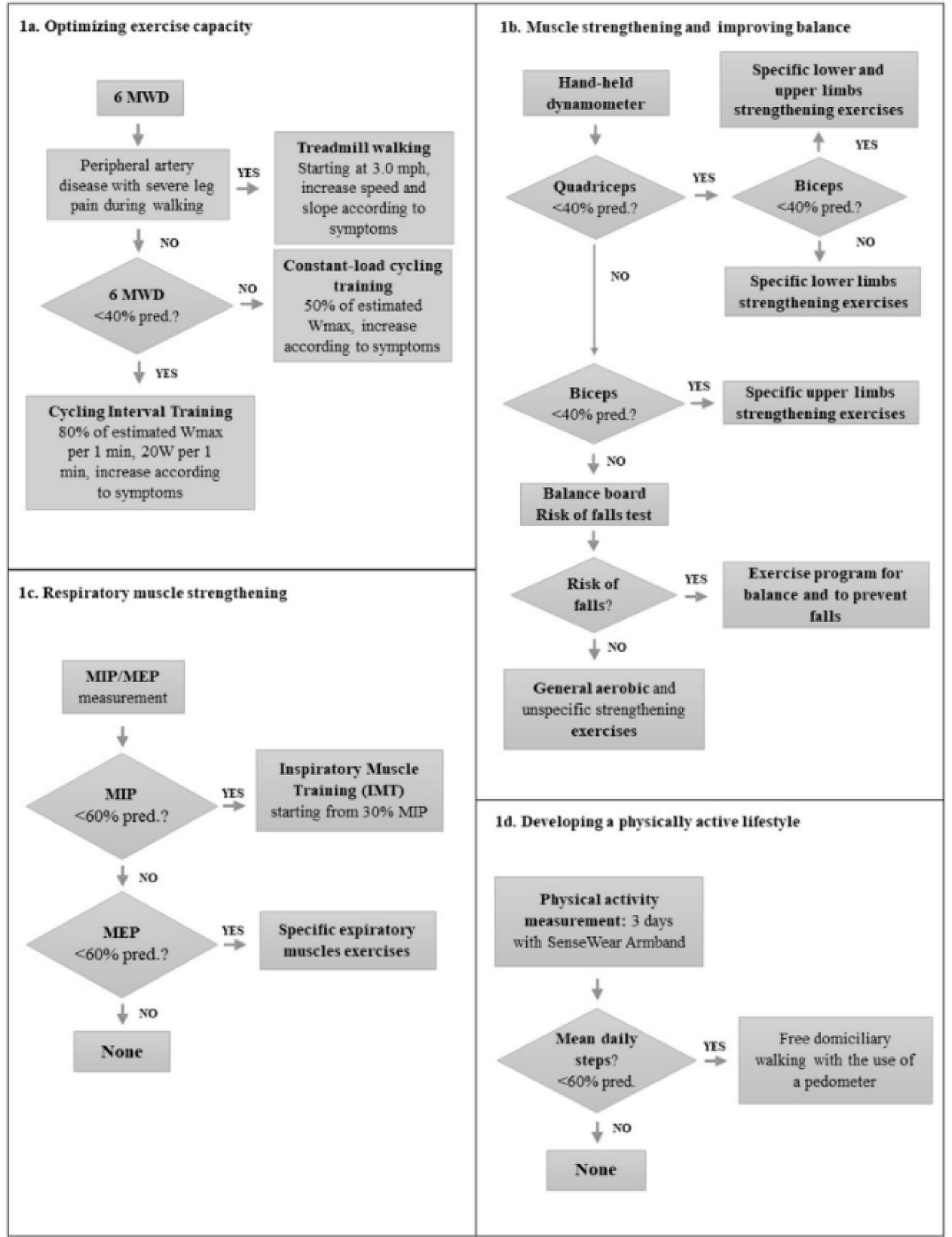

Figure 1. The algorithm developed in the audit process and used as a guide to train subjects with heart and lung diseases. 6MWD: 6-min Walk Distance; MEP: Maximal Expiratory Pressure; MIP: Maximal Inspiratory Pressure.

A dedicated computerized chart was created. In detail:

a. The proposed measurements were:

1. 6 min walking distance (6MWD), according to the American Thoracic Society/European Respiratory Society (ATS/ERS) guidelines [17], using the predicted values by Chetta et al. [18]. The minimum clinically important difference (MCID) for 6MWD is $30.5 \mathrm{~m}$ [19]

2. Maximal voluntary contraction (MVC) of biceps and quadriceps muscles through hand-held dynamometry using the predicted values by Andrews et al. [20]; the MCID for quadriceps and biceps strength is $0.76 \mathrm{~kg}$ [21]. Muscle weakness was defined as MVC $<60 \%$ of the predicted values

3. Maximal inspiratory (MIP) and expiratory pressures (MEP), according to the ATS/ERS guidelines [22]; the predicted values were those by Black and Hyatt [23] 
4. Stability index and risk of fall index, assessed by means of a balance board, with the predicted values of Cho et al. [24]

5. Domiciliary physical activity assessing daily steps [25]. The MCID is an increase of 1100 steps/day [26,27].

b. The proposed programs were:

1. Aerobic training (moderate-high intensity continuous or interval cycle training, treadmill walking, arm ergometer) $[1,6]$

2. Calisthenics $[1,2,6-8]$

3. Lower and/or upper limb selective muscle strengthening $[1,6]$

4. Balance training including core stability training, standing on unstable surfaces, balance boards, walking on tips and heels [28]

5. Inspiratory muscle training [29-32]

6. Domiciliary walking with pedometer $[33,34]$.

For further information on CREMA development see Supplementary Materials.

\subsection{Application of the CREMA}

Our physiotherapists prospectively (from January 2015 to December 2018) used the CREMA as a guide to set an individually tailored supervised exercise program consisting of 20 sessions, with 2 to 4 per week, lasting $2 \mathrm{~h}$ each. The first two sessions were dedicated to baseline assessments; the results were used to set the program according to the CREMA, personalizing the components, and FITT prescribed for each individual. Initial exercise intensity was set by CREMA and progression of intensity of each component of prescribed exercises in subsequent sessions was based on symptoms of dyspnea and fatigue as assessed by the Borg scale [35] according to Maltais et al. [36]. Intensity of exercise was increased when Borg scale for fatigue and dyspnea was lower of 5 at the end of each session. All patients in each diagnosis group underwent the same assessments, which were repeated at the end of training. The number and percentage of patients prescribed each single component was collected. All training sessions took place in the gym room under physiotherapist supervision. In addition, all patients attended an educational session once a week to learn about chronic disease management, diet, drugs, and healthy lifestyle. Medications were optimized at the beginning of the program. A multidisciplinary team composed of physiotherapists, physicians, a psychologist, nutritionist, and occupational therapist took care of diet, airway clearance, psychological or social issues, and other aspects.

\subsection{Feasibility and Safety}

Feasibility was investigated in terms of: (i) the type and number of prescriptions administered; (ii) the number of cases in which the physiotherapist had to change the initial prescription. Safety was investigated in terms of major and minor side effects. Major side effects were defined as events threatening the health of the patient requiring interruption of the program for specialist consultation and/or medical intervention. Minor side effects were defined as meaningful events of lower clinical severity inducing the stop of training for a maximum of 1-2 sessions, possibly but not necessarily requiring an adjustment of drug therapy [37].

For details on safety, feasibility and sensibility of CREMA see Supplementary Materials.

\subsection{Data Management and Statistical Analysis}

Data were collected from the Automated Integrated Health Care Record (AIHCR). Results are expressed as mean (standard deviation) for continuous data and as percentage for categorical and binary ones. All subjects were divided into 4 groups according to the main discharge diagnosis requiring the highest health resources consumption under the ICD9 classification:

- Obstructive: Patients with chronic obstructive pulmonary disease (COPD) with or without chronic respiratory failure, or asthma according to the ICD9 classification. COPD was defined according 
to the Global Initiative for Chronic Obstructive Lung Disease (GOLD) criteria [38], and asthma according to the Global Initiative for Asthma (GINA) criteria [39]. In patients with lung diseases, dynamic and static lung volumes were assessed according to the American Thoracic Society (ATS) guidelines [40] by means of a body plethysmograph or a water-sealed spirometer. The predicted values were those of Quanjer et al. [41].

- Restrictive: Patients with interstitial lung diseases, obesity hypoventilation syndrome, kyphoscoliosis, or mixed diagnoses with forced vital capacity (FVC) $<80 \%$ of predicted and with Forced Expiratory Volume at $1 \mathrm{~s}\left(\mathrm{FEV}_{1}\right) / \mathrm{FVC}>70 \%$.

- $\quad$ Chronic heart disease (CHD): Patients with chronic heart failure (CHF), according to the 2016 European Society of Cardiology guidelines [42], and coronary artery disease (CAD), according to the criteria of the European Society of Cardiology [43].

- $\quad$ REVASC: Patients that have undergone a coronary artery by-pass graft (CABG) or percutaneous transluminal coronary angioplasty (PTCA) in the previous 3 months.

Cardiac and respiratory comorbidities were also recorded from the main secondary discharge diagnoses according to the ICD9 classification.

Patients with primary diagnosis not included in the above groups (e.g., oncological, neurological, neuromuscular, locomotor diseases) or with the aforementioned diagnoses with locomotor limitations or contraindications to exercise were excluded.

Baseline data were compared among the different diagnoses, and the percentage of patients showing a severe impairment was calculated as follows. For 6MWD, quadriceps and biceps MVC, MIP, MEP, and balance, severe impairment was defined as a value $<60 \%$ of the predicted. Reduced physical activity was defined as $<3300$ steps/day. The percentage of improvers in each measure was compared by means of $\mathrm{X}^{2}$ test.

Differences between baseline characteristics and outcome measures for each group were evaluated by one-way analysis of variance (ANOVA) for continuous variables, and by $\mathrm{X}^{2}$ evaluation for categorical ones. A pairwise post-hoc analysis was performed if the primary evaluation was significant using Bonferroni correction. A p-value lower than 0.05 was considered significant.

\section{Results}

Figure 2 shows the flow diagram of the study. Of the 707 outpatients ( 384 with lung and 323 with heart diseases) admitted during the study period, 87 patients were excluded. Data of 92 of the 620 included patients were not analyzed for different reasons. Therefore, data of 528 patients were analyzed.

Table 1 shows the characteristics of the patient sample. Cardiac comorbidities were observed in $19.7 \%$ of respiratory patients while $11.0 \%$ of cardiac patients suffered from respiratory comorbidities. Patients with heart diseases had higher 6MWD, quadriceps, biceps, and expiratory muscle strength than those with lung diseases. The Restrictive group was the most severely impaired, such that more than half of those patients had a severe reduction in the 6MWD, and one-fifth had a reduced balance index; the difference was significant compared to the two cardiac groups (CHD and REVASC; Table 2). 


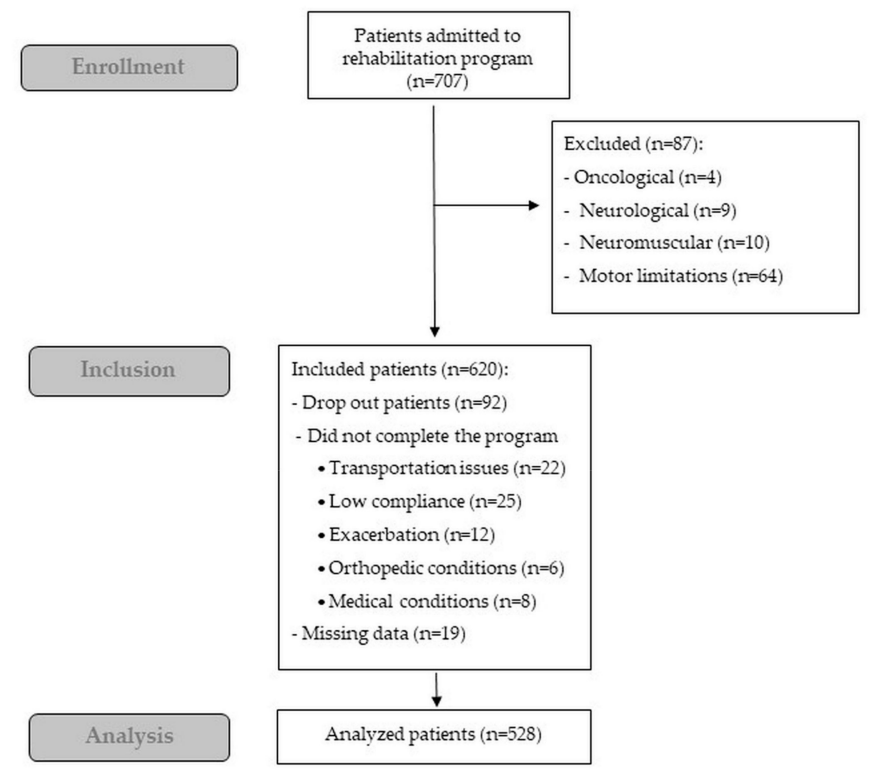

Figure 2. Flow diagram of the study.

Table 1. Demographic, anthropometric, physiological, and clinical characteristics of patients. Data are expressed as number (\%) or mean (SD).

\begin{tabular}{|c|c|c|c|c|c|c|}
\hline & All & $\begin{array}{l}\text { Obstructive } \\
\text { (O) }\end{array}$ & $\begin{array}{l}\text { Restrictive } \\
\text { (R) }\end{array}$ & CHD & REVASC (RE) & $p$-Value \\
\hline \multirow[t]{2}{*}{$N(\%)$} & 620 & $320(51.6)$ & $55(8.9)$ & $154(24.8)$ & $91(14.9)$ & \\
\hline & & $\begin{array}{l}\text { COPD }=205 \\
\text { COPD + CRF } \\
=67 \\
\text { Asthma }=48\end{array}$ & $\begin{array}{l}\text { ILD }=10 \\
\text { OHS }=6 \\
\text { Other RS }=39\end{array}$ & $\begin{array}{l}\mathrm{CHF}=36 \\
\mathrm{CAD}=118\end{array}$ & $\begin{array}{l}\mathrm{PTCA}=59 \\
\mathrm{CABG}=32\end{array}$ & \\
\hline Age, years & $67.1(10.5)$ & $68.3(9.0)$ & $65.1(14.2)$ & $67.6(9.9)$ & $63.0(12.7)$ & $\begin{array}{l}<0.001 \text { (RE vs. } \mathrm{O}<0.001 ; \text { RE vs. } \\
\mathrm{CHD}=0.006 \text { ) }\end{array}$ \\
\hline BMI, $\mathrm{Kg} / \mathrm{m}^{2}$ & $27.9(10.4)$ & $27.2(13.5)$ & $27.4(7.6)$ & $29.4(5.3)$ & $28.0(4.3)$ & 0.160 \\
\hline $\mathrm{FEV}_{1}, \%$ pred & & $62.5(23.1)$ & $69.9(32.9)$ & & & \\
\hline FVC, \%pred & & $88.6(20.5)$ & $72.6(31.2)$ & & & \\
\hline $\mathrm{FEV}_{1} / \mathrm{FVC}, \%$ & & $71.2(20.3)$ & $92.1(20.3)$ & & & \\
\hline LVEF, \% & & & & $55.6(11.3)$ & $57.8(7.3)$ & \\
\hline $6 \mathrm{MWD}$, meters & 442.5 (108.6) & $434.2(106.0)$ & $391.4(110.8)$ & $447.3(109.1)$ & $492.3(97.2)$ & $\begin{array}{l}<0.001 \text { ( } R \text { vs. } \mathrm{O}=0.04 ; \mathrm{RE} \text { vs. } \mathrm{O} \\
<0.001 ; \mathrm{CHD} \text { vs. } \mathrm{R}=0.006 ; \mathrm{RE} \text { vs. } \\
\mathrm{R}<0.001 ; \mathrm{RE} \text { vs. } \mathrm{CHD}=0.006 \text { ) }\end{array}$ \\
\hline Quadriceps MVC, Kg & $30.8(11.3)$ & $29.8(10.4)$ & $25.7(8.9)$ & $32.0(12.4)$ & $35.5(12.1)$ & $\begin{array}{l}<0.001 \text { (RE vs. } \mathrm{O}<0.001 ; \mathrm{CHD} \text { vs. } \\
\mathrm{R}<0.001 ; \mathrm{RE} \text { vs. } \mathrm{R}<0.001 \text { ) }\end{array}$ \\
\hline $\begin{array}{l}\text { Quadriceps MVC, } \\
\text { \%pred }\end{array}$ & $80.3(26.1)$ & $79.7(25.6)$ & $72.4(27.6)$ & $81.0(26.1)$ & $85.63(26.6)$ & 0.030 (RE vs. $\mathrm{R}=0.02$ ) \\
\hline Biceps MVC, Kg & $21.3(7.5)$ & $20.8(7.3)$ & $19.0(7.2)$ & $22.1(7.8)$ & $23.1(7.2)$ & $\begin{array}{l}0.003 \text { (CHD vs. } R=0.04 ; \text { RE vs. } R \\
=0.006)\end{array}$ \\
\hline Biceps MVC, \%pred & $92.4(23.1)$ & $92.56(24.4)$ & $90.37(23.49)$ & $92.71(22.15)$ & $92.54(20.26)$ & 0.955 \\
\hline MIP, $\mathrm{cmH}_{2} \mathrm{O}$ & $74.1(24.6)$ & $74.2(22.6)$ & $64.0(24.1)$ & $74.6(27.8)$ & $78.7(24.4)$ & $\begin{array}{l}0.006(\mathrm{R} \text { vs. } \mathrm{O}=0.02 ; \mathrm{CHD} \text { vs. } \mathrm{R}= \\
0.04 ; \mathrm{RE} \text { vs. } \mathrm{R}<0.001)\end{array}$ \\
\hline $\mathrm{MEP}, \mathrm{cmH}_{2} \mathrm{O}$ & $103.4(38.4)$ & $101.1(34.6)$ & $81.8(39.7)$ & $108.0(40.7)$ & $116.8(40.2)$ & $\begin{array}{l}0.006 ; \text { CHD vs. } R<0.001 ; \& \text { RE vs } \\
R<0.001 \text { ) }\end{array}$ \\
\hline MEP, $\%$ pred & $57.5(18.2)$ & $56.76(17.3)$ & $49.4(20.2)$ & $59.3(18.3)$ & $61.6(18.7)$ & $\begin{array}{l}0.006 \text { (R vs. } \mathrm{O}=0.04 ; \mathrm{CHD} \text { vs } \mathrm{R}= \\
0.006 ; \mathrm{RE} \text { vs. } \mathrm{R}<0.001 \text { ) }\end{array}$ \\
\hline
\end{tabular}

Note: 6MWD: 6 min walk distance; BMI: Body mass index; CABG: Coronary artery bypass graft; CAD: Coronary artery disease; CHD: Chronic heart diseases; CHF: Chronic heart failure; COPD: Chronic obstructive pulmonary disease; CRF: Chronic respiratory failure; FEV1: Forced expiratory volume at 1st second; FVC: Forced vital capacity; ILD: Interstitial lung disease; LVEF: Left ventricle ejection fraction; MEP: Maximal expiratory pressure; MIP: Maximal inspiratory pressure; MVC: Maximal voluntary capacity; Obstructive: Chronic airway diseases; Other RS: Other restrictive syndromes; OHS: Obesity-hypoventilation syndrome; PTCA: Percutaneous transluminal coronary angioplasty; Restrictive: Pulmonary restrictive diseases; REVASC: Recent myocardial revascularization. 
Table 2. Percentage of patients with impairment in baseline assessments.

\begin{tabular}{|c|c|c|c|c|c|c|}
\hline & All & Obstructive & Restrictive & CHD & REVASC & $p$-Value \\
\hline $6 \mathrm{MWD}<60 \%$ of pred. & 33.2 & 36.6 & 52.7 & 29.9 & 15.4 & $\begin{array}{l}<0.001 \text { (RE vs. } \mathrm{O}<0.001 ; \mathrm{CHD} \\
\text { vs. } \mathrm{R}=0.010 ; \mathrm{RE} \text { vs. } \mathrm{R}<0.001 \text { ) }\end{array}$ \\
\hline MVC quadriceps $<60 \%$ of pred. & 22.2 & 23.7 & 29.1 & 20.8 & 15.4 & 0.210 \\
\hline MVC biceps $<60 \%$ of pred. & 6.77 & 6.25 & 12.73 & 5.84 & 6.59 & 0.330 \\
\hline MIP $<60 \%$ of pred. & 21.4 & 19.1 & 32.7 & 20.1 & 25.3 & 0.174 \\
\hline MEP $<60 \%$ of pred. & 57.3 & 58.1 & 65.4 & 55.8 & 51.6 & 0.410 \\
\hline Risk of fall index & 36.9 & 35.3 & 36.4 & 41.6 & 35.16 & 0.592 \\
\hline Reduced physical activity & 29.0 & 31.9 & 30.9 & 27.3 & 20.9 & 0.210 \\
\hline
\end{tabular}

Note: 6MWD: 6 min walk distance; CHD: Chronic heart diseases; MEP: Maximal expiratory pressure; MIP: Maximal inspiratory pressure; Obstructive: Chronic airway diseases; Restrictive: Pulmonary restrictive diseases; REVASC: Recent myocardial revascularization. For 6MWD, lower and upper limb muscles, MIP, MEP, and balance, a severe impairment was defined when the measured value was lower than the $60 \%$ of the expected value. Reduced physical activity was defined as less than 3300 steps/day.

\section{Feasibility and Safety}

The mean time needed to complete the baseline assessment, insert data into the computerized chart, and obtain the training prescription was 40.3 (8.5) min per patient. Patients performed 20.2 (5.4) training sessions, and 538 patients $(86.8 \%)$ concluded the program without any need to change the exercise prescription. In 56 patients $(9.0 \%$; Obstructive $8.7 \%$, Restrictive, $18.2 \%$, CHD $8.4 \%$ and REVASC $4.4 \% p=0.067)$, the intensity of exercise was reduced during the program, while in $38(6.1 \%)$ some components of the training program (inspiratory muscle training or domiciliary walking) were not administered due to low compliance without any significant difference among groups.

The number and type of components of the exercise program administered to each group are reported in Table 3. No major side effect was observed. Minor side effects occurred in 69 patients $(11.1 \%)$ with 38 episodes of oxygen desaturation, 4 episodes of frequent ectopic ventricular beats, and 17 cases of abnormal arterial blood pressure (lower than $80 / 50$ or higher than $160 / 110 \mathrm{mmHg}$ ) during exercise. None of these episodes resulted in interruption of the program. There was no significant difference in the number of patients experiencing side effects among groups.

Table 3. Rate of prescription of program components by diagnosis group.

\begin{tabular}{lcccccc}
\hline & All & Obstructive & Restrictive & CHD & REVASC & $p$-Value \\
\hline Constant-load cycling & 61.3 & 54.1 & 45.4 & 70.1 & 75.8 & $<0.001$ \\
Interval training cycling & 33.5 & 40.3 & 47.3 & 27.9 & 18.7 & $<0.001$ \\
Treadmill training & 4.4 & 5.0 & 5.4 & 1.9 & 5.5 & 0.410 \\
Arms endurance training & 0.7 & 1.2 & 1.8 & 0 & 0 & 0.320 \\
General strengthening & 82.1 & 81.9 & 74.5 & 83.1 & 89.0 & 0.160 \\
Selective leg strengthening & 11.3 & 13.1 & 14.5 & 12.3 & 5.5 & 0.220 \\
Selective arm strenghtening & 4.0 & 3.1 & 5.4 & 1.9 & 5.5 & 0.390 \\
Selective arm+leg strengthening & 2.5 & 1.9 & 5.4 & 2.6 & 0 & 0.160 \\
Balance training & 29.1 & 31.3 & 30.6 & 37.8 & 5.7 & $<0.001$ \\
Inspiratory muscle training & 20.8 & 18.4 & 27.3 & 19.6 & 26.9 & 0.197 \\
Pedometer & 27.7 & 29.7 & 30.6 & 29.4 & 15.9 & 0.067 \\
\hline
\end{tabular}

Note: CHD: Chronic heart diseases; Obstructive: Chronic airway diseases; Restrictive: Pulmonary restrictive diseases; REVASC: Recent myocardial revascularization.

Table 4 shows the post training changes in outcome measures, as delta score (absolute values) and percentage of baseline. The changes differed among diagnosis groups, with REVASC improving 6MWD and MIP more than the Obstructive group. Only the REVASC group increased the mean daily steps, while the respiratory groups actually worsened. 
Table 4. Post training delta changes in outcomes measures (delta absolute value and delta \% of baseline).

\begin{tabular}{|c|c|c|c|c|c|c|}
\hline & All & Obstructive & Restrictive & CHD & REVASC & $p$-Value \\
\hline 6MWD, meters & $29.3(59.3)$ & $23.9(60.0)^{*}$ & $29.9(53.0)^{*}$ & $28.6(59.6)^{*}$ & $48.7(56.1)^{*}$ & 0.012 (RE vs. \\
\hline$\%$ of baseline & 8.13 & 7.03 & 9.16 & 8.12 & 11.43 & $\mathrm{O}=0.006)$ \\
\hline $\begin{array}{l}\text { Quadriceps } \\
\text { MVC, Kg } \\
\% \text { of baseline }\end{array}$ & $\begin{array}{l}3.0(8.0) * \\
14.0\end{array}$ & $\begin{array}{l}2.9(8.0) \\
13.6\end{array}$ & $\begin{array}{l}4.0(6.9) * \\
20.2\end{array}$ & $\begin{array}{l}3.1(7.5) * \\
13.4\end{array}$ & $\begin{array}{l}2.8(9.5) * \\
12.8\end{array}$ & 0.850 \\
\hline $\begin{array}{l}\text { Biceps MVC, } \mathrm{kg} \\
\% \text { of baseline }\end{array}$ & $\begin{array}{l}2.1(4.5) * \\
12.0\end{array}$ & $\begin{array}{l}1.9(4.0) * \\
12.0\end{array}$ & $\begin{array}{l}1.4(4.9) \\
9.1\end{array}$ & $\begin{array}{l}2.2(5.1) * \\
11.1\end{array}$ & $\begin{array}{l}3.1(5.0) * \\
15.4\end{array}$ & 0.160 \\
\hline $\begin{array}{l}\mathrm{MIP}, \mathrm{cmH}_{2} \mathrm{O} \\
\% \text { of baseline }\end{array}$ & $\begin{array}{l}5.8(13.7) * \\
10.4\end{array}$ & $\begin{array}{l}4.6(12.5) * \\
7.9\end{array}$ & $0.9(11.4) 4.1$ & $\begin{array}{l}7.8(15.0) * \\
15.6\end{array}$ & $\begin{array}{l}9.6(15.4)^{*} \\
14.9\end{array}$ & $\begin{array}{l}0.001 \text { (RE vs. } \\
\mathrm{O}=0.030 ; \\
\mathrm{CHD} \text { vs } \mathrm{R}= \\
0.020 ; \mathrm{RE} \text { vs } \mathrm{R} \\
=0.006)\end{array}$ \\
\hline $\begin{array}{l}\mathrm{MEP}, \mathrm{cmH}_{2} \mathrm{O} \\
\% \text { of baseline }\end{array}$ & $\begin{array}{l}8.5(27.6)^{*} \\
11.8\end{array}$ & $\begin{array}{l}8.5(27.4) * \\
12.0\end{array}$ & $\begin{array}{l}12.6(30.9) * \\
19.0\end{array}$ & $\begin{array}{l}4.9(26.0) * \\
7.2\end{array}$ & $\begin{array}{l}12.3(28.6) * \\
14.2\end{array}$ & 0.220 \\
\hline $\begin{array}{l}\text { Risk of fall index } \\
\% \text { of baseline }\end{array}$ & $\begin{array}{l}-0.6(1.5)^{*} \\
-4.3\end{array}$ & $\begin{array}{l}-0.6(1.6)^{*} \\
-3.6\end{array}$ & $\begin{array}{l}-0.7(1.3)^{*} \\
-4.1\end{array}$ & $\begin{array}{l}-0.6(1.5)^{*} \\
-6.1\end{array}$ & $\begin{array}{l}-0.4(1.2) \\
4.0\end{array}$ & 0.900 \\
\hline $\begin{array}{l}\text { Daily steps, n/day } \\
\% \text { of baseline }\end{array}$ & $\begin{array}{l}-132.5 \\
(3051.6)^{*} \\
-2.4\end{array}$ & $\begin{array}{l}-447.2 \\
(2618.6) * \\
-8.6\end{array}$ & $\begin{array}{l}-944.5 \\
(1986.0)^{*} \\
-20.7\end{array}$ & $\begin{array}{l}-77.2 \\
(3701.1) \\
-1.4\end{array}$ & $\begin{array}{l}1087.2 \\
(3297.1) * \\
18.4\end{array}$ & $\begin{array}{l}0.004 \text { (RE vs. } \\
O=0.006 ; R E \\
\text { vs } R=0.040 \text { ) }\end{array}$ \\
\hline
\end{tabular}

Note: 6MWD: 6 min walk distance; CHD: Chronic heart diseases; MEP: Maximal expiratory pressure; MIP: Maximal inspiratory pressure; MVC: Maximal voluntary capacity; Obstructive: Chronic airway diseases; Restrictive: Pulmonary restrictive diseases; REVASC: Recent myocardial revascularization. Data are expressed as mean (standard deviation). ${ }^{*} p$-value $<0.05$ pre to post variation within each group.

Overall, $69.9 \%, 63.8 \%$, and $61.2 \%$ of patients improved more than the MCID for quadriceps MVC, biceps MVC, and daily steps, respectively. There was no significant difference among groups in the percentage of improvers in quadriceps or biceps MVC, or daily steps. REVASC group showed the highest percentage of improvers in 6MWD (50.6\%) when compared to other groups (Obstructive $34.1 \%$, Restrictive $37.5 \%$, and CHD $37.8 \%$ ).

After the program, the male patients improved their MEP (by $5.3(1.5 \%)$ vs $2.3(12 \%), p=0.037$ ) and biceps strength $(10.3(19.7 \%)$ vs $6.0(17.5 \%), p=0.023)$ more than females. No other differences between males and females were found in post program changes.

\section{Discussion}

This study shows that the therapist driven protocol, based on a common battery of evaluations, including exercise training, tailored to individual patients with heart or lung diseases is feasible and safe. A recent survey study carried out in the Netherlands showed that there is poor implementation of cardiac rehabilitation guidelines in daily practice [12], despite the evidence that large-scale implementation of a clinical protocol for cardiac rehabilitation can lead to a substantial increase in guideline adherence [44].

In previous decision support systems $[13,14]$ the authors proposed only training, as main outcome measure referring to specific diseases. A therapist driven protocol like that produced by CREMA might allow better adherence to guidelines, and individually tailored programs with multiple evaluations and outcomes. The computerized decision support system has also increased the information available on the response to different prescriptions, providing feedback to improve the quality of the treatment [14].

Using the CREMA led to overall differences in the type of programs and exercises indicated for patients, with a substantial portion of exercise devoted to interval and balance training (Table 3). With the CREMA it was also possible to deliver different prescriptions among the different diagnoses. For example, inspiratory muscle training was prescribed only in $18.4 \%$ of the Obstructive group, i.e., those with MIP $<60 \%$ predicted. This is in accordance with recent findings of clinical trials in patients with COPD [45].

To our knowledge, no previous studies have the changes in functional and physical status after rehabilitation across different diseases. We found that REVASC patients had a more preserved functional capacity, which improved in the majority of patients, with the highest percentage of improvers in 
6MWD. An explanation may be that the REVASC patients did not suffer from any chronic condition when they entered the training program after an acute event.

The only between groups difference in post program improvement in outcome measures was observed in inspiratory muscle strength which was significantly higher in CHD as compared to Restrictive patients. This is in line with Evans et al. [10], who did not find any difference in the response to training between chronic airway obstruction and $\mathrm{CHF}$, and suggests that chronic diseases, irrespective of the diagnosis, may share some impairments of the systems involved in exercise performance, such as peripheral muscle dysfunction, respiratory muscle overload, cardiopulmonary limitation, and comorbidities. Otherwise Restrictive patients were the group with a minor response to rehabilitative intervention presenting the lowest mean baseline values in respiratory and peripheral muscles (Table 1), with the highest prevalence of impairment ( $<60 \%$ of predicted, Table 2$)$, indicating a generalized and severe muscle dysfunction.

In our study, REVASC patients improved daily steps more than those with pulmonary diseases. A huge variability has been reported in changes in physical activity after pulmonary rehabilitation [33,34]. Considering the overall results, given the high variability of the improvement in daily steps, both in pulmonary and cardiac diseases, we think that a better behavioral approach aimed at improving lifestyles and reducing sedentary behavior in chronic patients should be implemented and added to the training program.

Only $34 \%$ of our patients with COPD were responders to training improving the MCID of 6MWD. At the best of our knowledge, randomized controlled trials of exercise training in patients with COPD report about one-third of non-responders, and many papers have been dedicated (mostly unsuccessful) to find any predictive factor of success. Our lower percentage of improvers as compared to previous literature may be explained on the basis of the more restrictive criteria of improvement we used. This is one of the reasons leading to search for multifactorial outcomes after rehabilitation and tailored programs [46]. Previous literature has shown that the percentage of non-responders to training programs ranged from $14 \%$ to $23 \%$ in patients with CAD or CHF [47-49].

Cardiac [1] and respiratory rehabilitation programs [2] are safe, with a low incidence of major events but, to our knowledge, no studies have assessed the safety of a common training program for cardiac and respiratory patients combined. Our program was safe and the minor side effects observed in a few patients are in line with similar programs proposed in the aforementioned patients.

\subsection{Limitations of the Study}

As a retrospective and real-life study, we defined groups according to the administrative ICD9 classification. The reported comorbidity occurrence in our study must not be considered as a real prevalence as our patients did not undergo any specific diagnostic test. Furthermore, we did not assess the post exercise impact of the diseases or health related quality of life.

\subsection{Practical Implication}

The CREMA protocol based on present guidelines is useful for the assessment and prescription of training, as part of the multidisciplinary approach for personalized management of cardiac and pulmonary diseases, based on thorough assessment of treatable traits [50]. Protocols driving the training prescription may be included in the routine practice to administer exercise, ensuring adherence to the guidelines, and customizing the treatment to the individual patient.

\section{Conclusions}

Based on a common set of evaluations, our therapist driven protocol to tailor rehabilitation programs in patients with heart or lung diseases was feasible and safe. There were differences according to diagnoses, both in terms of functional capacity at the beginning of the program and the results obtained, with a better outcome in patients with recent myocardial revascularization than in those with chronic cardiac or respiratory diseases. 
Future studies are needed to demonstrate whether this instrument will play an important role in achieving the aims of health care including better outcomes, lower cost of care, and improved experience for patients and staff.

Supplementary Materials: The following are available online at http://www.mdpi.com/1660-4601/17/3/1016/s1.

Author Contributions: Conceptualization, C.S. and M.P.; Methodology, C.S.; Validation, C.S., N.A., and M.P.; Formal Analysis, C.S. and M.P.; Investigation, S.S., F.R., M.S., A.G.F., I.S., and R.G.; Resources, F.R., M.S., A.G.F., I.S., and R.G.; Data Curation, C.S. and M.P.; Writing - Original Draft Preparation, C.S., M.V., N.A., and M.P.; Writing - Review \& Editing, C.S, M.V., N.A., S.S., F.R., M.S., A.G.F., I.S., R.G., and M.P.; Visualization, C.S. and M.P.; Supervision, M.V. and S.S.; Project Administration, C.S. and M.P. All authors have read and agreed to the published version of the manuscript.

Funding: This work was supported by the "Ricerca Corrente" Funding scheme of the Ministry of Health, Italy.

Acknowledgments: The Authors thank Rosemary Allpress for the English revision of the manuscript, Laura Comini for criticism and editing, and Adriana Olivares for technical support.

Conflicts of Interest: The Authors have no conflict of interest to disclose related to the manuscript.

\section{References}

1. Spruit, M.A.; Singh, S.J.; Garvey, C.; ZuWallack, R.; Nici, L.; Rochester, C.; Hill, K.; Holland, A.E.; Lareau, S.C.; Man, W.D.; et al. An official American Thoracic Society/European Respiratory Society statement: Key concepts and advances in pulmonary rehabilitation. Am. J. Respir. Crit. Care Med. 2013, 188, e13-e64. [CrossRef] [PubMed]

2. Perk, J.; De Backer, G.; Gohlke, H.; Graham, I.; Reiner, Z.; Verschuren, W.M.; Albus, C.; Benlian, P.; Boysen, G.; Cifkova, R.; et al. European Guidelines on Cardiovascular Disease Prevention in Clinical Practice (version 2012). The Fifth Joint Task Force of the European Society of Cardiology and other societies on cardiovascular disease prevention in clinical practice (constituted by representatives of nine societies and by invited experts). G. Ital. Cardiol. 2013, 14, 328-392.

3. Casaburi, R.; Patessio, A.; Ioli, F.; Zanaboni, S.; Donner, C.F.; Wasserman, K. Reductions in exercise lactic acidosis and ventilation as a result of exercise training in patients with obstructive lung disease. Am. Rev. Respir. Dis. 1991, 143, 9-18. [CrossRef] [PubMed]

4. Anderson, L.; Oldridge, N.; Thompson, D.R.; Zwisler, A.D.; Rees, K.; Martin, N.; Taylor, R.S. Exercise-Based Cardiac Rehabilitation for Coronary Heart Disease: Cochrane Systematic Review and Meta-Analysis. J. Am. Coll. Cardiol. 2016, 67, 1-12. [CrossRef] [PubMed]

5. Taylor, R.S.; Sagar, V.A.; Davies, E.J.; Briscoe, S.; Coats, A.J.; Dalal, H.; Lough, F.; Rees, K.; Singh, S. Exercise-based rehabilitation for heart failure. Cochrane Database Syst. Rev. 2014, 4, CD003331. [CrossRef] [PubMed]

6. Mezzani, A.; Hamm, L.F.; Jones, A.M.; McBride, P.E.; Moholdt, T.; Stone, J.A.; Urhausen, A.; Williams, M.A. Aerobic exercise intensity assessment and prescription in cardiac rehabilitation: A joint position statement of the European Association for Cardiovascular Prevention and Rehabilitation, the American Association of Cardiovascular and Pulmonary Rehabilitation and the Canadian Association of Cardiac Rehabilitation. Eur. J. Prev. Cardiol. 2013, 20, 442-467.

7. Piepoli, M.F.; Binno, S.; Corrà, U.; Seferovic, P.; Conraads, V.; Jaarsma, T.; Schmid, J.P.; Filippatos, G.; Ponikowski, P.P. Committee on Exercise Physiology \& Training of the Heart Failure Association of the ESC. ExtraHF survey: The first European survey on implementation of exercise training in heart failure patients. Eur. J. Heart Fail. 2015, 17, 631-638.

8. Vogiatzis, I.; Rochester, C.L.; Spruit, M.A.; Troosters, T.; Clini, E.M. Increasing implementation and delivery of pulmonary rehabilitation: Key messages from the new ATS/ERS policy statement. Eur. Respir. J. 2016, 47, 1336-1341. [CrossRef]

9. Maestri, R.; Bruschi, C.; Fracchia, C.; Pinna, G.D.; Fanfulla, F.; Ambrosino, N. Physiological and clinical characteristics of patients with COPD admitted to an inpatient pulmonary rehabilitation program: A real-life study. Pulmonology 2019, 25, 71-78. [CrossRef]

10. Evans, R.A.; Singh, S.J; Collier, R.; Loke, I.; Steiner, M.C.; Morgan, M.D. Generic, symptom based, exercise rehabilitation; integrating patients with COPD and heart failure. Respir. Med. 2010, 104, 1473-1481. [CrossRef] 
11. Man, W.D.; Chowdhury, F.; Taylor, R.S.; Evans, R.A.; Doherty, P.; Singh, S.J.; Booth, S.; Thomason, D.; Andrews, D.; Lee, C.; et al. Building consensus for provision of breathlessness rehabilitation for patients with chronic obstructive pulmonary disease and chronic heart failure. Chron. Respir. Dis. 2016, 13, 229-239. [CrossRef] [PubMed]

12. Ford, R.M. Therapist-Driven Protocols: New Incentives for Change. Respir. Care 2015, 60, 757-759. [CrossRef] [PubMed]

13. Achttien, R.J.; Vromen, T.; Staal, J.B.; Peek, N.; Spee, R.F.; Niemeijer, V.M.; Kemps, H.M.; Panel, M.E. Development of evidence-based clinical algorithms for prescription of exercise-based cardiac rehabilitation. Neth. Heart J. 2015, 23, 563-575. [CrossRef] [PubMed]

14. Hansen, D.; Dendale, P.; Coninx, K.; Vanhees, L.; Piepoli, M.F.; Niebauer, J.; Cornelissen, V.; Pedretti, R.; Geurts, E.; Ruiz, G.R.; et al. The European Association of Preventive Cardiology Exercise Prescription in Everyday Practice and Rehabilitative Training (EXPERT) tool: A digital training and decision support system for optimized exercise prescription in cardiovascular disease. Concept, definitions and construction methodology. Eur. J. Prev. Cardiol. 2017, 24, 1017-1031. [PubMed]

15. Hasson, F.; Keeney, S.; McKenna, H. Research guidelines for the Delphi survey technique. J. Adv. Nurs. 2000, 32, 1008-1015. [PubMed]

16. Humphrey-Murto, S.; Varpio, L.; Wood, T.J.; Gonsalves, C.; Ufholz, L.A.; Mascioli, K.; Wang, C.; Foth, T. The use of the Delphi and other consensus group methods in medical education research: A Review. Acad. Med. 2017, 92, 1491-1498. [CrossRef]

17. Holland, A.E.; Spruit, M.A.; Troosters, T.; Puhan, M.A.; Pepin, V.; Saey, D.; McCormack, M.C.; Carlin, B.W.; Sciurba, F.C.; Pitta, F.; et al. An official European Respiratory Society/American Thoracic Society technical standard: Field walking tests in chronic respiratory disease. Eur. Respir. J. 2014, 44, 1428-1446. [CrossRef]

18. Chetta, A.; Zanini, A.; Pisi, G.; Aiello, M.; Tzani, P.; Neri, M.; Olivieri, D. Reference values for the 6-min walk test in healthy subjects 20-50 years old. Respir. Med. 2006, 100, 1573-1578. [CrossRef]

19. Bohannon, R.W.; Crouch, R. Minimal clinically important difference for change in 6-min walk test distance of adults with pathology: A systematic review. J. Eval. Clin. Pract. 2017, 23, 377-381. [CrossRef]

20. Andrews, A.W.; Thomas, M.W.; Bohannon, R.W. Normative values for isometric muscle force measurements obtained with hand-held dynamometers. Phys. Ther. 1996, 76, 248-259. [CrossRef]

21. Vaidya, T.; Beaumont, M.; de Bisschop, C.; Bazerque, L.; Le Blanc, C.; Vincent, A.; Ouksel, H.; Chambellan, A. Determining the minimally important difference in quadriceps strength in individuals with COPD using a fixed dynamometer. Int. J. Chron. Obstruct. Pulmon. Dis. 2018, 13, 2685-2693. [CrossRef] [PubMed]

22. American Thoracic Society/European Respiratory Society. ATS/ERS Statement on respiratory muscle testing. Am. J. Respir. Crit. Care Med. 2002, 166, 518-624. [CrossRef] [PubMed]

23. Black, L.F.; Hyatt, R.E. Maximal respiratory pressures: Normal values and relationship to age and sex. Am. Rev. Respir. Dis. 1969, 99, 696-702. [PubMed]

24. Cho, K.H.; Bok, S.K.; Kim, Y.J.; Hwang, S.L. Effect of lower limb strength on falls and balance of the elderly. Ann. Rehabil. Med. 2012, 36, 386-393. [CrossRef] [PubMed]

25. Armstrong, M.; Winnard, A.; Chynkiamis, N.; Boyle, S.; Burtin, C.; Vogiatzis, I. Use of pedometers as a tool to promote daily physical activity levels in patients with COPD: A systematic review and meta-analysis. Eur. Respir. Rev. 2019, 28, 190039. [CrossRef] [PubMed]

26. Teylan, M.; Kantorowski, A.; Homsy, D.; Kadri, R.; Richardson, C.; Moy, M. Physical activity in COPD: Minimal clinically important difference for medical events. Chron. Respir. Dis. 2019, 16, 1479973118816424. [CrossRef] [PubMed]

27. Tudor-Locke, C.; Craig, C.L.; Aoyagi, Y.; Bell, R.C.; Croteau, K.A.; De Bourdeaudhuij, I.; Ewald, B.; Gardner, A.W.; Hatano, Y.; Lutes, L.D.; et al. How many steps/day are enough? For older adults and special populations. Int. J. Behav. Nutr. Phys. Act. 2011, 8, 80. [CrossRef]

28. Hakamy, A.; Bolton, C.E.; McKeever, T.M. The effect of pulmonary rehabilitation on mortality, balance, and risk of fall in stable patients with chronic obstructive pulmonary disease. Chron. Respir. Dis. 2017, 14, 54-62. [CrossRef]

29. Wu, J.; Kuang, L.; Fu, L. Effects of inspiratory muscle training in chronic heart failure patients: A systematic review and meta-analysis. Congenit. Heart Dis. 2018, 13, 194-202. [CrossRef] 
30. Charususin, N.; Gosselink, R.; Decramer, M.; Demeyer, H.; McConnell, A.; Saey, D.; Maltais, F.; Derom, E.; Vermeersch, S.; Heijdra, Y.F.; et al. Randomised controlled trial of adjunctive inspiratory muscle training for patients with COPD. Thorax 2018, 73, 942-950. [CrossRef]

31. Hermes, B.M.; Cardoso, D.M.; Gomes, T.J.; Santos, T.D.; Vicente, M.S.; Pereira, S.N.; Barbosa, V.A.; Albuquerque, I.M. Short-term inspiratory muscle training potentiates the benefits of aerobic and resistance training in patients undergoing CABG in phase II cardiac rehabilitation program. Rev. Bras. Cir. Cardiovasc. 2015, 30, 474-481. [PubMed]

32. Kendall, F.; Oliveira, J.; Peleteiro, B.; Pinho, P.; Bastos, P.T. Inspiratory muscle training is effective to reduce postoperative pulmonary complications and length of hospital stay: A systematic review and meta-analysis. Disabil Rehabil. 2018, 40, 864-882. [CrossRef] [PubMed]

33. Ter Hoeve, N.; Sunamura, M.; Stam, H.J.; Boersma, E.; Geleijnse, M.L.; van Domburg, R.T.; van den Berg-Emons, R.J.G. Effects of two behavioral cardiac rehabilitation interventions on physical activity: A randomized controlled trial. Int. J. Cardiol. 2018, 255, 221-228. [CrossRef] [PubMed]

34. Widyastuti, K.; Makhabah, D.N.; Setijadi, A.R.; Sutanto, Y.S.; Ambrosino, N. Benefits and costs of home pedometer assisted physical activity in patients with COPD. A preliminary randomized controlled trial. Pulmonology 2018, 24, 211-218. [CrossRef]

35. Borg, G. Perceived exertion as an indicator of somatic stress. Scand. J. Rehabil. Med. 1970, 2, $92-98$.

36. Maltais, F.; LeBlanc, P.; Jobin, J.; Berube, C.; Bruneau, J.; Carrier, L.; Breton, M.J.; Falardeau, G.; Belleau, R. Intensity of training and physiologic adaptation in patients with chronic obstructive pulmonary disease. Am. J. Respir. Crit. Care Med. 1997, 155, 555-561. [CrossRef]

37. Goodrich, D.E.; Larkin, A.R.; Lowery, J.C.; Holleman, R.G.; Richardson, C.R. Adverse events among high-risk participants in a home-based walking study: A descriptive study. Int. J. Behav. Nutr. Phys. Act. 2007, 4, 20. [CrossRef]

38. Global Initiative for Chronic Obstructive lung Disease. Global Strategy for the Diagnosis, Management and Prevention of Chronic Obstructive Pulmonary Disease (2019 Report). Available online: www.goldcopd.org (accessed on 21 November 2019).

39. Global Initiative for Asthma. Global Strategy for Asthma Management and Prevention. 2019. Available online: www.ginasthma.org (accessed on 15 December 2019).

40. Culver, B.H.; Graham, B.L.; Coates, A.L.; Wanger, J.; Berry, C.E.; Clarke, P.K.; Hallstrand, T.S.; Hankinson, J.L.; Kaminsky, D.A.; MacIntyre, N.R.; et al. ATS Committee on Proficiency Standards for Pulmonary Function Laboratories. Recommendations for a Standardized Pulmonary Function Report. An Official American Thoracic Society Technical Statement. Am. J. Respir. Crit. Care Med. 2017, 196, 1463-1472. [CrossRef]

41. Quanjer, P.H.; Stanojevic, S.; Cole, T.J.; Baur, X.; Hall, G.L.; Culver, B.H.; Enright, P.L.; Hankinson, J.L.; Ip, M.S.; Zheng, J.; et al. Multi-ethnic reference values for spirometry for the 3-95-yr age range: The global lung function 2012 equations. Eur. Respir. J. 2012, 40, 1324-1343. [CrossRef]

42. Ponikowski, P.; Voors, A.A.; Anker, S.D.; Bueno, H.; Cleland, J.G.F.; Coats, A.J.S.; Falk, V.; González-Juanatey, J.R.; Harjola, V.P.; Jankowska, E.A.; et al. 2016 ESC Guidelines for the diagnosis and treatment of acute and chronic heart failure: The Task Force for the diagnosis and treatment of acute and chronic heart failure of the European Society of Cardiology (ESC)Developed with the special contribution of the Heart Failure Association (HFA) of the ESC. Eur. Heart J. 2016, 37, 2129-2200.

43. Montalescot, G.; Sechtem, U.; Achenbach, S.; Andreotti, F.; Arden, C.; Budaj, A.; Bugiardini, R.; Crea, F.; Cuisset, T.; Di Mario, C.; et al. 2013 ESC guidelines on the management of stable coronary artery disease: The Task Force on the management of stable coronary artery disease of the European Society of Cardiology. Eur. Heart J. 2013, 34, 2949-3003. [PubMed]

44. Goud, R.; de Keizer, N.F.; ter Riet, G.; Wyatt, J.C.; Hasman, A.; Hellemans, I.M.; Peek, N. Effect of guideline based computerised decision support on decision making of multidisciplinary teams: Cluster randomised trial in cardiac rehabilitation. BMJ 2009, 338, b1440. [CrossRef]

45. Ambrosino, N. Inspiratory muscle training in stable COPD patients: Enough is enough? Eur. Respir. J 2018, 51, 1702285. [CrossRef] [PubMed]

46. Spruit, M.A.; Augustin, I.M.; Vanfleteren, L.E.; Janssen, D.J.; Gaffron, S.; Pennings, H.J.; Smeenk, F.; Pieters, W.; van den Bergh, J.J.; Michels, A.J.; et al. CIRO+ Rehabilitation Network. Differential response to pulmonary rehabilitation in COPD: Multidimensional profiling. Eur. Respir. J. 2015, 46, 1625-1635. [CrossRef] 
47. De Schutter, A.; Kachur, S.; Lavie, C.J.; Menezes, A.; Shum, K.K.; Bangalore, S.; Arena, R.; Milani, R.V. Cardiac rehabilitation fitness changes and subsequent survival. Eur. Heart J. Qual. Care Clin. Outcomes 2018, 4, 173-179. [CrossRef] [PubMed]

48. Witvrouwen, I.; Pattyn, N.; Gevaert, A.B.; Possemiers, N.; Van Craenenbroeck, A.H.; Cornelissen, V.A.; Beckers, P.J.; Vanhees, L.; Van Craenenbroeck, E.M. Predictors of response to exercise training in patients with coronary artery disease-A subanalysis of the SAINTEX-CAD study. Eur. J. Prev. Cardiol. 2019, 26, 1158-1163. [CrossRef] [PubMed]

49. Schmid, J.P.; Zurek, M.; Saner, H. Chronotropic incompetence predicts impaired response to exercise training in heart failure patients with sinus rhythm. Eur. J. Prev. Cardiol. 2013, 20, 585-592. [CrossRef]

50. Wouters, E.F.M.; Wouters, B.B.R.E.; Augustin, I.M.L.; Houben-Wilke, S.; Vanfleteren, L.E.G.W.; Franssen, F.M.E. Personalised pulmonary rehabilitation in COPD. Eur. Respir. Rev. 2018, 27, 170125. [CrossRef]

(C) 2020 by the authors. Licensee MDPI, Basel, Switzerland. This article is an open access article distributed under the terms and conditions of the Creative Commons Attribution (CC BY) license (http://creativecommons.org/licenses/by/4.0/). 